УДК $316+338.48$

$10.17213 / 2075-2067-2020-6-102-110$

\title{
МОЛОДЕЖНЫЙ ТУРИЗМ В ФОКУСЕ СОЦИОЛОГИЧЕСКОЙ РЕФЛЕКСИИ
}

\author{
(C) 2020 г. К. Э. Рожабова
}

\section{Южно-Российский государственный политехнический университет (НПИ) имени М. И. Платова, г. Новочеркасск, Россия}

Целью исследования является освещение дискурсивных практик, сложсившихся в соичологической науке относительно такого явления, как молодежный туризм с точки зрения наиболее актуальных проблем в жизни современной российской молодежс. Среди них: рост молодежной девиации, снижение сочиального здоровья молодежи, распространение инфантильности и апатии в молодежной среде и др.

Методологическую базу исследования представляют принципы типологического анализа, позволивщего показать многообразие видов и форм молодежного туризма, а также дискурсивного подхода, использование которого определил сам ракурс исследования, связанный с осмыслением дискурсивного пространства в области молодежного туризма в российском обществе.

Результаты исследования. Молодежный туризм - важный сегмент туристической сферы общества, а сама молодежь - самый перспективный, с точки зрения реальных и будущих туристических практик, участник туристического движения в современном мире. Однако, в отличие от других стран в России молодежный туризм ещзе только начинает разворачиваться в масштабное туристическое движение, имея при этом достаточно впечатляющую историю своего развития в недалеком советском прошлом на основе эффективной государственной политики.

Перспективу исследования составляет вывод о необходимости развития этого кластера российского туризма, который вбирает в себя огромное разнообразие туристских практик. Особый акцент необходимо сделать на социальном молодежном туризме как реальном механизме развития индустрии молодежного туризма в целом.

Ключевые слова: молодежь; туризм; молодежный туризм; соичиальный туризм; спортивный туризм; социализачия; социальное здоровье.

\section{YOUTH TOURISM IN THE FOCUS OF SOCIOLOGICAL REFLECTION}

\author{
(C) 2020 K. E. Rozhabova
}

\section{Platov South Russian State Polytechnic University (NPI), Novocherkassk, Russia}

The purpose of the research is to highlight the discursive practices that have developed in sociological science regarding such a phenomenon as youth tourism from the point of view of the most pressing problems in the life of modern Russian youth. Among them: the growth of youth deviation, the decline in social health of young people, the spread of infantilism and apathy in the youth environment, etc.

Methodological basis of research are principles of typological analysis, which allowed to show the variety of types and forms of youth tourism and the discursive approach, which determined 
the perspective of the research associated with the understanding of discursive space in the field of youth tourism in the Russian society.

Research result. Youth tourism is an important segment of the tourism sector of society, and young people themselves are the most promising, in terms of real and future tourism practices, participants in the tourist movement in the modern world. However, unlike other countries, youth tourism in Russia is just beginning to develop into a large-scale tourist movement, while having a rather spectacular history of its development in the recent Soviet past on the basis of an effective state policy.

The perspective of the research is the conclusion about the need to develop this cluster of Russian tourism, which includes a huge variety of tourist practices. Special emphasis should be placed on social youth tourism as a real mechanism for the development of the youth tourism industry as a whole.

Key words: youth; tourism; youth tourism; social tourism; sports tourism; socialization; social health.

Введение. Молодежный туризм активно развивается в современном мире, получая свое оформление по самым различным направлениям, и этому есть объяснение. Прежде всего, этот сектор туризма наиболее значим для развития экономической структуры общества, так как молодежь принимает активное участие в туристских практиках. Кроме того, туризм позволяет сохранить физическое и духовное здоровье молодежи и, следовательно, нации, что особенно актуально для российской действительности, в которой вопросы снижения социального здоровья молодежи стоят далеко не на последнем месте в ряду самых злободневных проблем $[1,2]$.

В данной связи внимание исследователей совершенно естественным образом все чаще привлекают вопросы теории и практики в области молодежного туризма. В этом направлении работают такие исследователи, как А. В. Васильцов, Д. В. Коноплева, Д. С. Ахатов [3], С.В. Булганина, К.В. Ананьева, Н. С. Тюмина, Ю.Г. Шутова [3], Н.С. Мартышенко [5], М.Ю. Раитина, Г.И. Илюхина, Е.М. Покровская, Т.И. Суслова, М.М. Ходкевич [6], И.Н. Насибова [7, 8], Т.А. Юдина, М.Н. Баланян [9] и другие. На уровне научного дискурса поднимаются различные вопросы: проблемы молодежного туризма, его типы и особенности развития в условиях российской действительности, влияние основных акторов на становление молодежного туризма в России, его влияние на формирование ценностных и поведенческих установок молодежи, ее патриотическое сознание. Последнее формируется в процессе знакомства с родным краем, богатством родной природы, культурными достижениями своего народа, их многообразия в палитре различных традиций, обычаев.

Через общение с природой, погружение в ее прекрасный мир, особенно в условиях компьютеризации молодежи цифровой эпохи, значительно изменившей образ жизни современных молодых людей (и не только молодых), формируется целостная концепция личности, ее энергетическое поле в единстве с энергией и силой, которыми наполнена природа. И в этой связи совершенно справедливо говорить об огромном социализационном потенциале туризма как пространства становления личности [10] через общение с природой во всем ее многообразии и величии лесов, полей, рек, озер, горных вершин и водопадов. И, если обратиться в не столь далекое прошлое российского государства, то можно обнаружить самое пристальное внимание к молодежному туризму как средству социализации молодежи. Речь идет о советском времени, когда с самых ранних лет советские дети погружались в мир природы через различные мероприятия воспитательной и учебно-образовательной направленности в детских садах, школах, вузах. В советском государстве активно практиковались различные спортивные мероприятия с выездом на природу, субботники, движения по защите окружающего мира среди под- 
ростков и молодежи. Существовала поддерживаемая государством сеть туристических клубов и организаций, в том числе и среди взрослого поколения, которое служило примером для молодежи. Активно вовлеченная в туристские практики советская молодежь таким образом осваивала социальные и культурные нормы, интегрировалась в систему социальных связей и культурных ценностей советского общества. В этом, безусловно, проявляется соцализационная роль туризма, его социокультурный потенциал [11].

Важнейшим аспектом изучения молодежного туризма, конечно же, является профилактика девиантного поведения молодежи, масштабы распространения которого представляют значительный риск для социального самочувствия как молодежи, так и всего российского общества $[12,13,14]$.

С этой точки зрения, молодежный туризм как предметное пространство социологической науки имеет не только и не столько теоретическую значимость, сколько значимость социальную, которая связана с поиском путей и стратегий повышения ценности туризма как социальной практики в молодежной среде. Однако этому поиску предшествует глубокий теоретический анализ такого явления, как молодежный туризм, на уровне которого рассматриваются различные типы туризма и его функции как социальной практики, привлекательной для молодежи.

Типологическое разнообразие молодежного туризма: общая характеристика. Молодежный туризм выступает важным агентом воспитания и социализации молодежи, а, следовательно, встает вопрос об использовании его социализационного потенциала, что определяет значимость анализа его типологической характеристики в условиях погруженности молодежи в медиапространство, сетевые технологии общения и познания, не предполагающие активный досуг, физические практики, передвижение в реальном пространстве, знакомство с природой, от которой молодежь все больше и больше дистанцируется [15].

Немало типологий туризма сложилось в научном дискурсе. Они опираются на разные индикаторы, среди которых ученые выделяют и форму организации туризма, и цель, и источник финансирования, и возраст учас- тников туристских групп, их число, средства передвижения и т.д. [16]. Мы не будем приводить многообразие типов и видов туризма, сложившихся в современном мире, так как не этот сюжет выступает ключевым в данной работе, но на некоторых не можем не остановиться. Так, согласно одной из типологий, выделяемой на основе стиля как принципа классификации, туризм может быть романтическим, «бродячим», семейным, дружественным, деловым и туризмом «по интересам» [16].

Интерес представляет также типология молодежного тризма, в которой выделяются нетрадиционные виды туристских практик, получающих или получивших развитие в молодежной среде. Среди них, отражающих специфические интересы молодежи, ее игровые интересы в условиях нового информационного общества, А.А. Баканова выделяет следующие [17]: dark-туризм (организованные поездки по городам-призракам с соответствующей амуницией, техническими средствами), ритуальный туризм (посещение старинных и заброшенных кладбищ, а также могил своих предков с ритуальными целями), индустриальный туризм (изучение различных инженерных сооружений, объектов, старинных сооружений производственного или хозяйственного назначения), кибер-гот-туризм (его возникновение связано с субкультурой «для людей будущего», представители которого полагают, что мир идет к своему логическому историческому апогею ввиду плохой экологии, компьютеризации жизни и человека, грядущей ядерной катастрофы).

Независимо от того, какой вид туризма определяет реализацию молодежных интересов, стремлений и потребностей, можно сказать, что молодежный туризм в его традиционных и нетрадиционных формах выступает способом и механизмом освоения культурного наследия и природного богатства мира. Он позволяет познакомиться с культурным многообразием своего отечества и окружающего мира, расширить границы познания в области природных ландшафтов, познать самого себя и интегрироваться в социум.

Особенное внимание в советском обществе уделяли спортивному туризму в его различных формах. Пеший, водный, горный, велосипедный и другие виды туризма позволяли испытать себя на прочность, расширить 
познания о природе, включиться в широкий круг спортивного (туристического) сообщества. И в современной российской реальности спортивные виды туризма активно развиваются, но уже в своем большинстве на коммерческой основе, что делает его доступным не для всей молодежи.

Получают развитие такие виды туризма, которые, будучи очень близкими по своей сути, получили название сельского, деревенского, аграрного, экологического, природного, зеленого. Они основываются на изучении родного края, его природы, истории и культуры, обычаев и традиций населения.

В последнее время все чаще в фокус внимания общественности и науки попадает социальный туризм, включающий в себя «любые виды активного отдыха, расходы на которые туристу полностью или частично компенсируются из социальных средств» [18]. Социальный туризм призван интегрировать в туристские практики и социум тех, кто не имеет возможности реализовать себя в туризме за свои собственные средства. Надо сказать, что социальный туризм - известная практика в России. По сути, до 80\% всего туристического сегмента СССР занимал этот вид туризма, и льготные туристические путевки, практически полностью оплаченные государством, особенное распространение получили в сфере детско-юношеского и молодежного туризма [19]. Сегодня социальный молодежный туризм как самостоятельное направление снова привлек внимание государства и по праву, ведь он позволяет сочетать возможность досуговые практики и социализацию его участников посредством «актуализации исторической памяти, расширения культурного кругозора, формирования гуманистического мышления и мировоззрения» [20].

Данные функции выполняет также такой вид туризма, как событийный туризм. Его развитие тоже актуализировалось в современную эпоху, когда общество развернулось к своей истории, к родному краю как объекту познания. Событийный туризм ориентирован на знакомство с историческими событиями и страницами своего государства, своего народа. При этом организуется возможность принять непосредственное участие в реконструируемых исторических событиях, что делает весьма привлекательным для молодежи этот вид туризма, однако, он еще не получил широкого распространения в российском обществе.

Молодежный туризм как предметное поле социологической рефлексии: актуальные проблемы исследования в условиях российской реальности. Молодежный туризм с точки зрения общественно-значимой практики представляет немаловажный интерес для российского социума, в котором кризис социализационного механизма и институтов социализации сформировал пространство разнообразных рисков социализации молодежи. Один из них, вмещающий в себе многие другие, связан с риском взросления и, как следствие, инфантилизации молодежи, не способной осуществлять жизнедеятельность в формате, адекватном своему возрасту [21]. Наблюдается как устойчивая тенденция неспособность молодежи к самостоятельному принятию решений и их реализации, рост социальной апатии в молодежной среде, снижение жизненного тонуса и физического здоровья молодежи, что, конечно же, говорит о неблагополучии не только и даже не столько молодежи, сколько всего российского общества. Тем не менее, необходимо решать возникающие проблемы, а потому мы хотим обозначить те из них, которые могут быть решены с помощью молодежного туризма. И с этой точки зрения важно посмотреть, что думают об этом ученые, специализирующиеся в данной предметной сфере социологии.

Изучая молодежный туризм в России, исследователи обращают внимание на исторические корни его развития в нашей стране, конечно же, апеллируя, прежде всего, к советскому опыту. Именно в советское время молодежный туризм приобрел статус одного из важнейших средств массовой физической культуры и спорта, активно развиваясь по различным направлениям и, прежде всего, в рамках спортивных туристских походов (пеших, водных, горных, велосипедных и др. с привлечением необходимых элементов физической культуры и спорта) [3]. Советское правительство осознавало огромную роль туризма в формировании дружеских связей между различными народами, населявшими CССР, решая тем самым проблемы национального единства и дружбы народов, сохранения и развития культуры населяющих 
СССР народов, укрепления международных связей, не забывая об экономических задачах, которые также решались за счет развития туристического кластера экономики.

В современной России туристический кластер экономики еще значительно уступает в своем развитии другим странам, но рынок туристических услуг продолжает развиваться в нашей стране по восходящей линии [22], если, конечно, не брать в расчет ситуацию пандемии коронавируса, которая затормозила этот положительный вектор развития молодежного туризма в России, как, собственно, и во всем мире.

В качестве проблемы, которая ставится учеными, анализирующими развитие молодежного туризма в России на современном этапе, обращает на себя внимание также проблема дифференциации этого вида туризма, совершенно очевидная и закономерная для социально поляризованного российского общества, но от этого не менее актуальная и рискогенная с точки зрения перспектив динамики молодежного сектора туристской сферы. И вновь вспоминается советский опыт, когда доступ к туристским услугам, к туризму как стилю жизни и способу интеграции в массовый спорт был свободным практически для всех слоев населения, а сам туризм выступал в роде некой национальной идеологии здоровья и социальной активности. В современном российском обществе ситуация складывается несколько иная. Сами туристские практики в молодежной среде на современном этапе можно рассматривать как показатель сложившихся различий между социальными слоями и группами молодежи. Некоторые туристские практики носят элитный характер. Это, в основном, практики из области спортивного туризма, отдельные виды которого весьма дорогостоящие, требуют серьезного (и, соответственно, дорогого) обмундирования, а также серьезных финансовых вложений в сами поездки, путешествия (к примеру, горнолыжный туризм). Поэтому, как пишут исследователи, стоит вопрос о социокультурной дифференциации молодежи в сфере туризма и необходимости социологической диагностики дифференциации туризма и его основных функций, мотивов, интересов и целей участия молодежи в туристской деятельности [23].
Анализ предпочтений молодежи в сфере туризма, проведенный российскими исследователями, показал, что, помимо интереса к различным видам отдыха и экскурсионным туристическим программам, российская молодежь проявляет значительный интерес к активным видам туризма спортивно-оздоровительного кластера, и среди них наиболее развитыми с точки зрения участия молодежи являются скалолазание, альпинизм, рафтинг, сплав на байдарках, ориентирование на местности, геораскопки [4]. Иными словами, территории российского государства представляют объект туристского интеpeca со стороны молодежи, а потому нуждаются в дальнейшем развитии и реализации своего туристского потенциала. И, действительно, сложно перечислить все регионы страны, уникальные по своему социокультурному, природному, историческому облику. Это и Дальний Восток, и Забайкалье, и Северный Кавказ, и многие другие. Развитие туристских практик посредством вовлечения в них молодежных масс позволит частично решить проблему региональной дезинтеграции, снижения уровня культуры межэтнического и межкультурного общения. Особенно актуальна данная проблема для полиэтничных регионов России, в которых тенденции социальной дезинтеграции выражены более критично. В процессе туристической деятельности выстраиваются коммуникативные связи, происходит обмен культурным и социальным опытом, формируются и закрепляются элементы и формы межэтнического общения. В эпоху информационного общества, когда значительная часть коммуникаций переместилась в виртуальное (сетевое) пространство, не обладающее таким же интегративным ресурсным потенциалом, как пространство реального общения, туристские практики приобретают особое значение, еще большее, нежели в доинформационную эпоху.

Среди российской молодежи сформировался достаточно высокий запрос на туристические услуги, но уровень вовлеченности молодежи в туристские практики, по мнению специалистов, остается пока невысоким в нашей стране, а, следовательно, потенциал молодежного туризма реализуется не полностью [6]. 
Выводы. Молодежный туризм представляет важнейший сегмент туристической сферы общества, а сама молодежь - самый перспективный, с точки зрения реальных и будущих туристических практик, участник туристического движения в России. Однако масштабы молодежного туризма на современный день значительно уступают зарубежным потокам туристов молодежного возраста. Причины этого связаны с факторами экономического неблагополучия большей части населения страны, в том числе и среди молодежи, а также с отсутствием эффективной политики и стратегии развития молодежного туризма в России во главе с концепцией туризма как идеологического базиса конструирования жизненных стратегий молодежи и значимой финансовой поддержкой данной концепции в рамках ее внедрения в реальной практике государственного управления. Нам могут возразить, апеллируя к принятой на уровне государства Стратегии развития туризма в России до 2035 года, в которой в том числе уделяется внимание развитию молодежного туризма [24], но мы отталкиваемся от реальных показателей и практик, которые пока не позволяют говорить о высоком качестве проведения туристских мероприятий в молодежной среде и масштабном характере развития молодежного туризма.

\section{Литература}

1. Гафиатулина Н.Х., Верещзагина А.В., Самыгин С.И. Социальное здоровье российской молодежи: риски разрушения в условиях глобализации // Гуманитарные, социально-экономические и общественные науки. 2017. - №10. - C. 26-31.

2. Гафиатулина Н.Х., Шевченко А.М., Самыгин С.И. Социальное здоровье студенческой молодежи с позиций концепции адаптации и адаптационных ресурсов // Гуманитарные, социально-экономические и общественные науки. - 2019. - №8. - С. 30-33.

3. Васильиов А.В., Коноплева Д.В., Ахатов Д. С. Историогенез молодежного туризма в России [Электронный ресурс]. - Peжим доступа: https://cyberleninka.ru/article/n/ istoriogenez-molodezhnogo-turizma-v-rossii.

4. Булганина С.В., Ананьева К.В., Тюмина Н.С., Шутова Ю.Г. Маркетинговое иссле- дование предпочтений молодёжи в области туризма [Электронный ресурс] // Интернет-журнал «НАУКОВЕДЕНИЕ». - 2016. - Т. 8. №4. - Режим доступа: http://naukovedenie.ru/ PDF/06EVN416.pdf.

5. Мартышшенко Н. С. Проблемы международного молодежного и студенческого туризма в Приморском крае // Новый университет. - 2011. - №10. - C. 21-23.

6. Раитина М. Ю., Илюхина Г. И., Покровская Е.М., Суслова Т.И., Ходкевич М.М. Молодежный туризм как способ культурной интеграции: региональный аспект (на примере г. Томска) // Сервис Plus. - 2019. - Т. 13. №2. - C. 3-13.

7. Насибова И.Н. Молодежный туризм как агент формирования патриотизма в молодежной среде российского общества: социализационный потенциал и оценка его эффективности: автореф. дис. ... канд. социол. наук: 22.00.04. — Ростов-на-Дону, 2016. - 39 с.

8. Насибова И.Н. Особенности развития молодежного туризма в России и его влияние на формирование патриотических ценностей молодежи // Гуманитарные, социальноэкономические и общественные науки. 2015. — №11. - C. 302-307.

9. Юдина Т.А., Баланян М.Н. Молодежный туризм как фактор развития международного туризма на территории Краснодарского края [Электронный ресурс]. - Режим доступа: http://teoria-practica.ru/rus/files/arhiv zhurnala/2015/5/sociology/yudina-balanian.pdf.

10. Михалева Ю.А. Туризм как одна из форм социализации личности [Электронный pecypc]. - Режим доступа: https://elis. psu.ru/node/387409.

11. Степановский Е. П., Скляров А. В. Социализация в туристском пространстве // Научный вестник ЮИМ. - 2015. - №4. C. 48-52.

12. Позднякова M.E. Особенности девиантного поведения современной российской молодежи: на пути криминализации и десоциализации // Россия реформирующаяся: ежегодник: вып. 15 / Отв. ред. М.К. Горшков. М.: Новый Хронограф, 2017. - С.516-548.

13. На пути к преступлению: девиантное поведение подростков и риски взросления в современной России (опыт социологического анализа). Коллективная монография / Под научн. ред. М.Е. Поздняковой и Т.А. Хагуро- 
ва. - Краснодар: Кубанский гос. ун-т; М.: Институт социологии РАН, 2012. - 344 с.

14. Экстремальность и экстремизм в социальных практиках российской молодёжи / [В. В. Брюно и др.]; отв. ред. Т.А. Хагуров, М. Е. Позднякова. - М.: ФНИСЦ РАН, Краснодар: Кубанский гос. ун-т, 2017. - 340 с.

15. Серебрякова О.В. Роль семьи в процессе формирования экологической культуры российской молодежи [Электронный ресурс] // Гуманитарные, социально-экономические и общественные науки. - 2014. - №3. - Режим доступа: http://www.online-science.ru/userfiles/ file/hyxiqqeidbsy4zlnjjstzcbiedglehjw.pdf.

16. Чан Фыонг Май. Классификация туризма в современном обществе // Общество: политика, экономика, право. - 2016. №6. - С. 66-57.

17. Баканова A.А. Нетрадиционные виды молодежного туризма // Царскосельские чтения. - 2012. - №XVI. - C. 149-152.

18. Социальный туризм: средства, стратегия, рынки [Электронный ресурс]. — Режим доступа: http://nb-forum.ru/useful/advices/ sosial-tourism-sredstva-strategiya-runki.

19. Путрик Ю.С. Государственное регулирование туризма как направление социальной политики в Российской Федерации [Электронный ресурс]. - Режим доступа: http://theoryofculture.ru/issues/2014 01/511/.

20. Каменеи А.В. Молодежный социальный туризм как общественная проблема [Электронный ресурс] // Современные проблемы науки и образования. - 2015. — №2-2. - Режим доступа: http://science-education.ru/ru/article/ view?id=22022.

21. Хагуров T.A. Девиации, социальный контроль и риски взросления в современной России [Электронный ресурс] // Вестник Института социологии. - 2013. - №7. - Peжим доступа: www.vestnik.isras.ru.

22. Коновалова Е. Е., Косарева Н.В. Развитие молодежного туризма в России [Электронный ресурс]. — Режим доступа: https://cyberleninka.ru/article/n/razvitiemolodyozhnogo-turizma-v-rossii.

23. Гозалова М.Р., Середина М.И. Социокультурная дифференциация молодежи в сфере туризма [Электронный ресурс]. - Peжим доступа: https:/cyberleninka.ru/article/n/ sotsiokulturnaya-differentsiatsiya-molodyozhiv-sfere-turizma.
24. Распоряжение Правительства РФ от 20 сентября 2019 г. №2129-р «О Стратегии развития туризма в РФ на период до 2035 г.» [Электронный ресурс]. — Режим доступа: https://www.garant.ru/products/ipo/prime/ $\operatorname{doc} / 72661648 /$.

\section{References}

1. Gafiatulina N.H., Vereshhagina A. V., Samygin S.I. Social'noe zdorov'e rossijskoj molodezhi: riski razrushenija $\mathrm{v}$ uslovijah globalizacii [Social health of Russian youth: risks of destruction in the context of globalization] // Gumanitarnye, social'no-jekonomicheskie i obshhestvennye nauki [Humanities, socio-economic and social Sciences]. — 2017. — №10. — Pp. 26-31.

2. Gafiatulina N. H., Shevchenko A. M., Samygin S.I. Social'noe zdorov'e studencheskoj molodezhi s pozicij koncepcii adaptacii i adaptacionnyh resursov [Social health of student youth from the standpoint of the concept of adaptation and adaptation resources] // Gumanitarnye, social'no-jekonomicheskie i obshhestvennye nauki [Humanities, socio-economic and social Sciences]. - 2019. - №8. - Pp. 30-33.

3. Vasil'cov A. V., Konopleva D. V., Ahatov D.S. Istoriogenez molodezhnogo turizma $\mathrm{V}$ Rossii [Historiogenesis of youth tourism in Russia] [Jelektronnyj resurs]. — URL: https://cyberleninka.ru/article/n/istoriogenez-molodezhnogoturizma-v-rossii.

4. Bulganina S.V., Anan'eva K. V., Tjumina N.S., Shutova Ju. G. Marketingovoe issledovanie predpochtenij molodjozhi v oblasti turizma [Marketing research of youth preferences in the field of tourism] [Jelektronnyj resurs]// Internet-zhurnal «NAUKOVEDENIE». 2016. - Vol. 8. - №4. - URL: http://naukovedenie.ru/PDF/06EVN416.pdf.

5. Martyshenko N.S. Problemy mezhdunarodnogo molodezhnogo i studencheskogo turizma v Primorskom krae [Problems of international youth and student tourism in Primorsky Krai] // Novyj universitet [New University]. 2011. - №10. - Pp. 21-23.

6. Raitina M. Ju., Iljuhina G.I., Pokrovskaja E.M., Suslova T.I., Hodkevich M.M. Molodezhnyj turizm kak sposob kul'turnoj integracii: regional'nyj aspekt (na primere g. Tomska) [Youth tourism as a way of cultural integration: regional aspect (on the example of Tomsk)]// 
Servis Plus. - 2019. - Vol. 13. - №2. Pp. 3-13.

7. Nasibova I.N. Molodezhnyj turizm kak agent formirovanija patriotizma $\mathrm{v}$ molodezhnoj srede rossijskogo obshhestva: socializacionnyj potencial i ocenka ego jeffektivnosti [Youth tourism as an agent of patriotism formation in the youth environment of the Russian society: socialization potential and evaluation of its effectiveness. Ph. D. (Sociology) Thesis: 22.00.04]. — Rostov-on-Don, 2016. - 39 p.

8. Nasibova I.N. Osobennosti razvitija molodezhnogo turizma v Rossii i ego vlijanie na formirovanie patrioticheskih cennostej molodezhi [Features of the development of youth tourism in Russia and its impact on the formation of Patriotic values of youth] // Gumanitarnye, social'no-jekonomicheskie i obshhestvennye nauki [Humanities, socio-economic and social Sciences]. — 2015. — №11. — Pp. 302-307.

9. Judina T.A., Balanjan M.N. Molodezhnyj turizm kak faktor razvitija mezhdunarodnogo turizma na territorii Krasnodarskogo kraja [Youth tourism as a factor in the development of international tourism in the Krasnodar territory] [Jelektronnyj resurs]. - URL: http://teoria-practica. ru/rus/files/arhiv_zhurnala/2015/5/sociology/ yudina-balanian.pdf.

10. Mihaleva Ju. A. Turizm kak odna iz form socializacii lichnosti [Tourism as one of the forms of socialization of the individual] [Jelektronnyj resurs]. — URL: https://elis.psu.ru/ node/387409.

11. Stepanovskij E.P., Skljarov A. V. Socializacija $\mathrm{v}$ turistskom prostranstve [Socialization in the tourist space] // Nauchnyj vestnik JuIM [Scientific Bulletin of YUIM]. — 2015. №4. - Pp. 48-52.

12. Pozdnjakova M.E. Osobennosti deviantnogo povedenija sovremennoj rossijskoj molodezhi: na puti kriminalizacii i desocializacii [Features of deviant behavior of modern Russian youth: on the way of criminalization and desocialization] // Rossija reformirujushhajasja: ezhegodnik: vyp. 15 / In M.K. Gorshkov (eds.). - Moscow: Novyj Hronograf, 2017. Pp. 516-548.

13. Na puti k prestupleniju: deviantnoe povedenie podrostkov i riski vzroslenija $\mathrm{v}$ sovremennoj Rossii (opyt sociologicheskogo analiza). Kollektivnaja monografija [On the way to crime: deviant behavior of teenagers and risks of growing up in modern Russia (experience of sociological analysis). Collective monograph] / In M.E. Pozdnjakova, T.A. Hagurov (eds.). Krasnodar: Kubanskij gos. un-t; Moscow: Institut sociologii RAN, 2012. - $344 \mathrm{p}$.

14. Jekstremal'nost' i jekstremizm v social'nyh praktikah rossijskoj molodjozhi [Extremality and extremism in social practices of Russian youth] / [V. V. Brjuno et al.]. In T.A. Hagurov, M.E. Pozdnjakova (eds.). Moscow: FNISC RAN, Krasnodar: Kubanskij gos. un-t, 2017. - $340 \mathrm{p}$.

15. Serebrjakova O.V. Rol' sem'i v processe formirovanija jekologicheskoj kul'tury rossijskoj molodezhi [The role of the family in the process of forming the ecological culture of Russian youth] [Jelektronnyj resurs] // Gumanitarnye, social'no-jekonomicheskie i obshhestvennye nauki [Humanities, socio-economic and social sciences]. — 2014. - №3. - URL: http://www.online-science.ru/userfiles/file/hyxiqqeidbsy4zlnjjstzcbiedglehjw.pdf.

16. Chan Fyong Maj. Klassifikacija turizma $\mathrm{v}$ sovremennom obshhestve [Classification of tourism in modern society] // Obshhestvo: politika, jekonomika, pravo [Society: politics, economics, law]. - 2016. — №6. - Pp. 66-57.

17. Bakanova A.A. Netradicionnye vidy molodezhnogo turizma [Non-traditional types of youth tourism] // Carskosel'skie chtenija [Tsarskoye Selo readings]. — 2012. — №XVI. Pp. 149-152.

18. Social'nyj turizm: sredstva, strategija, rynki [Social tourism: means, strategy, markets] [Jelektronnyj resurs]. — URL: http://nb-forum. $\mathrm{ru} /$ useful/advices/sosial-tourism-sredstva-strategiya-runki.

19. Putrik Ju. S. Gosudarstvennoe regulirovanie turizma kak napravlenie social'noj politiki v Rossijskoj Federacii [State regulation of tourism as a direction of social policy in the Russian Federation] [Jelektronnyj resurs]. — URL: http:// theoryofculture.ru/issues/2014_01/511/.

20. Kamenec A. $V$. Molodezhnyj social'nyj turizm kak obshhestvennaja problema [Youth social tourism as a public problem] [Jelektronnyj resurs] // Sovremennye problemy nauki i obrazovanija [Modern problems of science and education]. - 2015. — №2-2. — URL: http:// science-education.ru/ru/article/view? $\mathrm{id}=22022$.

21. Hagurov T.A. Deviacii, social'nyj kontrol' i riski vzroslenija v sovremennoj Rossii 
[Deviations, social control and risks of growing up in modern Russia] [Jelektronnyj resurs]// Vestnik Instituta sociologii [Bulletin of the Institute of sociology]. — 2013. — №7. - URL: www.vestnik.isras.ru.

22. Konovalova E.E., Kosareva N.V. Razvitie molodezhnogo turizma $\mathrm{v}$ Rossii [Development of youth tourism in Russia] [Jelektronnyj resurs]. — URL: https://cyberleninka.ru/ article/n/razvitie-molodyozhnogo-turizma-vrossii.

23. Gozalova M.R., Seredina M.I. Sociokul'turnaja differenciacija molodezhi $\mathrm{v}$ sfere turizma [Socio-cultural differentiation of youth in the field of tourism] [Jelektronnyj resurs]. URL: https://cyberleninka.ru/article/n/sotsiokulturnaya-differentsiatsiya-molodyozhi-v-sfereturizma.

24. Rasporjazhenie Pravitel'stva RF ot 20 sentjabrja 2019 g. №2129-r «O Strategii razvitija turizma v RF na period do 2035 g.» [Decree of the Government of the Russian Federation of September 20, 2019 №2129-r «On the strategy of tourism development in the Russian Federation for the period up to 2035»] [Jelektronnyj resurs]. - URL: https://www.garant.ru/products/ipo/prime/doc/72661648/.

Рожабова Камета Эльдархановна - аспирант ЮжноРоссийского государственного политехнического университета (НПИ) имени М.И. Платова.

Rozhabova Kameta Eldarkhanovna - Graduate Student, Platov South Russian State Polytechnic University (NPI).

346428, г. Новочеркасск, ул. Просвещения, 132

132 Prosveshcheniya st., 346528, Novocherkassk, Russia

E-mail: rozhabova77@mail.ru 